\title{
Journal of Economics Bibliography
}

www.kspjournals.org

\begin{tabular}{lll}
\hline Volume 5 & March 2018 & Issue 1 \\
\hline
\end{tabular}

\section{Critique of impact assessment of regional trade agreements using non-tariff measures}

\author{
By Rashmi BANGA ${ }^{\dagger}$
}

\begin{abstract}
Are cent study undertaken by Kawasaki (2017) uses a computable general equilibrium (CGE) model to estimate the impact of removal tariffs and non-tariff measures on trade flows and the overall gross domestic product (GDP) of the remaining 11 countries in the Trans-Pacific Partnership (TPP11) partner countries. This note attempts to provide insights into such estimations so as to help in real impact assessments of the tariff and nontariff provisions of agreements such as the TPP11. It warns that policy makers who seek to rely on such studies need to be aware of the large number of assumptions that underlie the quantification of the non-tariff measures, including that regulation is necessarily negative for trade, and other limitations of the methodology used. The paper also notes these are only one aspect of the broader economic impacts of an agreement that includes chapters on intellectual property, investor protections, government procurement, and state-owned enterprises, among others.
\end{abstract}

Keywords. International trade, Tariff, Non-tariff.

JEL. F10, F13, F15, J50.

\section{Introduction}

$\mathrm{R}$ ecently there has emerged a growing stream of literature which is analyzing the impact of removal of Non-Tariff Measures (NTMs) on trade flows as well as on overall gross domestic product (GDP) of a country. Attempts are being made to quantify NTMs by international organizations by providing anadvalorem equivalence (AVE) for NTMs. Given the complexity in measuring NTMs, quantifying NTMs can at best be described as work-in-progress, and using AVEs of NTMs to estimate impact of Regional Trade Agreements on GDP can be extremely misleading for the policy makers. One such study has been undertaken by Kawasaki (2017). Kawasaki (2017) uses a CGE model to estimate the impact of removal of AVEs of NTMs on GDP of the remaining 11 countries in the TransPacific Partnership (TPP11) partner countries.

The results of the study suggest that the maximum GDP gains from removal of $50 \%$ of NTMs will be experienced by Malaysiain TPP 11 ,as it will lead to an increase of $20.41 \%$ in real GDP which amounts to around US\$ 70 billion (around $29 \%$ of Malaysia exports of goods and services). Around a $20 \%$ increase in GDP due to removal of $50 \%$ of NTMs appears to be a bit far-fetched, and may not appeal to logic. It should be noted that models which estimate GDP gains due to reduction in AVE of NTMs have been recognized to have serious limitations, which have been widely accepted in the economic literature. For example, according to the United Nations Conference on Trade And Development (UNCTAD, 2013) " $^{\text {ii }}$ "It would be desirable to investigate how one can identify and separate the cost of welfare-enhancing dimension of NTMs, it is difficult to think of a methodology that would allow this to be carried out in a systematic way.

\footnotetext{
${ }^{\dagger}$ Unit of Economic Cooperation and Integration among Developing Countries (ECIDC), Division of Globalisation and Development Strategies (GDS), UNCTAD, Geneva.

๑. +0092515730280 ext 258

ㄱ. Rashmi.banga@unctad.org
} 


\section{Journal of Economics Bibliography}

Detailed information is needed; it would have to be provided by technical experts (Deardoff \& Stern, 1997) and probably only for specific products or a limited range of countries. All in all, standard Applied General Equilibrium Models (AGE) do not offer many ways to include demand-shift and supply shift effects and none of them are fully satisfactory".

The limitations of using such a methodology where CGE model is estimated to capture the impact of removal of NTMs, which are further estimated by AVEs, need to be reiterated so as to make the policymakers aware of the wide assumptions that are made in such analyses and the probability of multiple biases that may enter these analyses.

\section{Limitations of using CGE models}

The real GDP gains from the TPP11 due to tariff and non-tariff reductions in the Kawasaki study are based on computable general equilibrium (CGE) modelling. There exists a substantial economic literature that has criticized CGE models and questioned the results arrived by them ${ }^{\text {iii. }}$.

Three major criticisms which become very relevant to Kawasaki's study need to be considered.

Firstly, it has been well documented in the literature that CGE models are designed in such a manner that liberalization will always lead to increase in 'overall gains'. According to Taylor \& Arnim (2006), most of the CGE models assume (i) fixed or 'full' employment of labour and capital is maintained everywhere in the world; (ii) each country's trade deficit (or surplus) stays constant after liberalisation; and (iii) completely flexible taxes on households enable each country's internal economy to adjust smoothly. This implies that the models are designed in such a way that 'the price system' will always respond to liberalisation in a way that it leads to increases in overall well-being. In simple terms, the model assumes that the TPP country will have no budget deficit because if revenue from import tariffs falls due to the TPP's requirement to remove them, then other taxes will be successfully increased so that there is no revenue loss.

Second, many studies have pointed out the inconsistency in assumptions of CGE models. The 'Armington assumption' used in all CGE models, including this report, implies that there exists 'product differentiation' which means that no country, however small, produces something which is also produced by another country in the world. In other words, domestic and foreign products are imperfect substitutes. For example, it would assume milk produced by New Zealand will be different from milk produced by Canada. This assumption is not only unrealistic but can have far reaching implications on calculation of welfare effects in CGE models. For example, this will imply that CGE models underestimate the extent of domestic displacement that can take place due to imports of cheaper products.

Thirdly, CGE models estimate 'static gains' or 'long-term gains', ignoring shortterm 'adjustment costs' and therefore overestimate the 'total gains'. Most of the CGE models, including the one used by Kawasaki, provide static results i.e., change 'before' and 'after' a non-tariff change or a removal of AVEs. More importantly, the reduction of non-tariff measures (NTMs), which according to the study will be higher in case of Malaysia as compared to other TPP countries, will invariably entail both short term adjustment costs and long term social costs, which are completely neglected, overestimating the gains from removal of NTMs. Some of the important macroeconomic adjustment costs include immediate loss in trade competitiveness due to changed regulations and standards and subsequent job losses.

\section{Limitations of using NTMs}

The study using CGE modelling estimates the gains from NTM reduction in TPP11, but fails to highlight that purported gains from NTM removal will take place whether or not a country is part of TPP11. As emphasized in the paper by the 


\section{Journal of Economics Bibliography}

author and also quoting earlier study by Kawasaki $(2014,2015)$, - "it must be noted that what is essential to realize income gains by NTM reductions is own NTM reductions rather than those by trade partners in TPP and RTAs." Further, any reduction at the national level by a country, the gains of it will be available at MFN basis and not necessarily to only TPP partner countries. Therefore assuming that these gains from removing NTMs will come only by entering TPP11 is misleading. Further problems in using NTMs are:

What constitutes NTMs? A fundamental issue that has problematized the systematic study of NTMs has been a lack of precise consensus about what exactly constitutes a NTM and how they should be classified. At present there is no single, unified, comprehensive repository of information on NTMs, although attempts are being made at the international level. But these attempts are still preliminary steps. Even at the national level many governments have not attempted to place all the regulations that may impact on trade into a single database. Clearly, without being able to easily and accurately count the number and type of relevant NTMs, the study of their impacts on trade and welfare is hugely problematized.

NTMs may not necessarily be against welfare of the citizens. In fact, most NTMs are regulations which have been put in place to address market failures and for public good. As many NTMs - for instance regulations protecting consumer welfare-are introduced to tackle market failures arising from externalities, the welfare effects of their removal are less clear. In comparison with tariffs, it is harder to draw direct linkages between NTMs, trade and welfare using, for instance, general equilibrium models, as has been done in Kawasaki's study. Tariffs are generally recognised as driving up prices, thereby creating 'rents' which impose costs to overall consumer welfare. The impact of standards such as NTMs is more complex: they will generally reduce a products' supply by making production more expensive, but demand could potentially move either up or down depending on whether the response to higher prices is stronger or weaker than an increase in consumer demand for the newly regulated (and presumably now safer or higher quality) product.

Non-tariff measures may reduce trade and yet increase welfare in the country that applies the measure. The effects depend on the nature of the market failure that the measure addresses, the type of non-tariff measure used and other marketspecific circumstances. The trade and welfare effects of quality measures such as technical barriers to trade and sanitary and phytosanitary measures depend on whether they address genuine market failures. If a measure is applied only to protect domestic producers, both trade and welfare in the importing country decrease. If, however, the measure corrects a market failure, welfare is likely to increase with ambiguous effects on trade.

According to the World Bank (2013) and the United Nations Economic and Social Commission for Asia and the Pacific (UNESCAP, 2015) - "A further problem is that policy responses to these types of analysis are often framed in terms of removing NTMs in their entirety, thereby making the lowering of measures a 'success'. However, as NTMs are often introduced to serve legitimate public demands for better product safety or environmental protection, total removal may not be realistic, and in any case should be based on a wider analysis. Further, with many NTMs the real problems affecting businesses are often the result more of misapplication of the regulations, or the costs of compliance, rather than the stringency of the NTMs themselves."

The strength of the agreement in eliminating or harmonizing NTMs will vary by agreement but generally depends on a number of factors. Most important is the level of development of the parties. The closer the level of development between the parties the easier will be standards harmonization and mutual recognition of conformity assessment results. Given the parties in TPP11 are on different development trajectories, it will be extremely difficult to harmonise the regulations, say between Canada and Brunei.

JEB, 5(1), R. Banga, p.36-40. 


\section{Journal of Economics Bibliography}

Streamlining or reducing NTMs is sometimes seen by governments as a 'concession' to trading partners - analogous to a tariff reduction. While there are some similarities in the sense that NTMs can also restrict market access, the political economy of NTM reform can be quite different from tariff reform. By requiring expensive adaptations of production processes and costly demonstrations of compliance, NTMs may well push up the prices of products, making exports more costly (Cadot et al., 2015) and lowering trade competitiveness of the TPP countries concerned.

Another crucial factor which influences the depth of NTM commitments in trade agreements is the degree of prior similarities in regulatory approaches between the parties. In other words, where countries already apply similar types of regulation to similar products, harmonization or mutual recognition is likely to be simpler than when the same products are regulated by different types of 58 NTMs. The level of "regulatory distance" between regimes can be estimated by considering the extent to which products (at the six digit HS code level) are subject to the same types of NTMs (chosen from among the 122 categories given under the UNCTAD-MAST nomenclature). Regulatory distance between TPP11 partners is very high.

In addition to regulatory distance, countries may also vary in the stringency of their NTMs, that is, even if both countries apply the same type of sanitary and phytosanitary (SPS) measure - for instance, maximum residue levels - to the same products, one country may have tougher standards. This is harder to measure across countries, particularly for non-quantitative NTMs. Any impact assessment of removal of such NTMs will be biased as the degree of NTM cannot be captured through AVE methodology. The study by Kawasaki fails to be cognizant of this.

\section{Limitations of using AVEs of NTMs}

It is interesting to note that the results arrived at by removal of NTMs are not robust and can change depending on how they are introduced in the model. Fugazza \& Maur (2008) demonstrate the importance of modelling both the demand and supply-shift effects of technical measures in policy analysis using CGE models. Most importantly their simulation results underline substantial differences in effects, depending on whether AVEs are introduced using shocks on import tariffs or on technological change. They find that the sign of the welfare impact can be reversed in more than 50 per cent of the cases ${ }^{\text {iv }}$. They state that "A general finding is the very high sensitivity of welfare results to the policy variable of choice in the simulation. This makes any policy interpretation hazardous".

Furthermore, the following limitations of using AVEs need to be recognized while stating the results of the impact of removal of AVEs on GDP.

Estimation of AVE of NTMs is fraught with a number of problems. For example, the equivalence between tariffs and quotas breaks down in the presence of market uncertainty. Furthermore, the AVE of NTMs does not capture any relevant fixed costs, such as those associated with meeting certain technical regulations.

AVEs do not adequately capture the trade-restrictive impact of certain non-tariff measures when the production process is fragmented across countries because they fail to take into account the cumulative effect of measures along the production chain. Additionally, in the case of services measures, the estimated AVEs neither account for the possible substitution between different modes of supply nor for the complementarity between trade in services and trade in goods.

Trade agreements like the TPP11 that harmonize standards are likely to present "hub-and-spoke" characteristics, with the larger partner representing the hub to whose standards the spokes conform. This tendency may hinder further trade opening among major regional groupings. Secondly, "deep" preferential trade agreements? (PTAs) (that is, more ambitious PTAs in terms of the depth of integration of technical barriers to trade? (TBT) provisions) are more likely between countries at higher and similar levels of development.

JEB, 5(1), R. Banga, p.36-40. 


\section{Journal of Economics Bibliography}

In the presence of market uncertainty or when NTMs take the form of fixed market entry costs, NTMs can have different effects than tariffs. Another weakness of AVEs is that they only provide an estimate of the overall effect of non-tariff measures which cannot be decomposed by measure. In the case of the technical barriers to trade and sanitary and phytosanitary measures, more specifically, empirical evidence confirms that these may either increase or decrease trade and that harmonisation and mutual recognition are ways in which any negative trade effects can be mitigated.

Convergence towards international standards, which is encouraged in the agreements on technical barriers to trade and sanitary and phytosanitary measures, creates tensions in practice. International standards may be difficult to use and preferences may vary among TPP11 countries. Also, the capacity to influence international standard setting may differ among countries.

In addition, it should be noted that CGE studies address only the tariff and nontariff measures of these agreements. They do not recognize or seek to calculate the broader economic impacts of chapters on intellectual property, investor protections, government procurement, and state-owned enterprises, among others.

\section{Notes}

i GDP (constant 2010 US\$) of Malaysia is \$343 billion in 2016 (World Bank).

ii [Retrieved from].

iii For a detail critique see [Retrieved from].

${ }^{\text {iv }}$ [Retrieved from].

\section{References}

Cadot, O., Asprilla, A., Gourdon, J., Knebel, C., \& Peters, R. (2015). Deep regional integration and non-tariff measures: A methodology for data analysis. UNCTAD. [Retrieved from].

Deardorff, A.V., \& Stern, R. (1997). Measurement of non-tariff barriers. OECD Economics Department Working Papers, No.179. doi. 10.1787/568705648470

Fugazza, M., \& Maur, J.C. (2008). Non-tariff barriers in CGE models: how useful for policy? Journal of Policy Modeling. 30(3), 475-490. doi. 10.1016/j.jpolmod.2007.10.001

Kawasaki, K. (2017). Emergent uncertainty in regional integration -economic impacts of alternative RTA scenarios, MPRA Working Paper, [Retrieved from].

Taylor, L., \& von Arnim, R. (2006). Computable General Equilibrium Models of Trade Liberalization: The Doha Debate, New School for Social Research.Oxford: Oxfam GB.

UNESCAP, (2015). Trade and Non-tariff Measures: Impacts in the Asia-Pacific Region, UNESCAP, [Retrieved from].

World Bank, (2013). Making Trade Policy More Transparent: A New Database of Non-Tariff Measures, Economic Premise, 128, [Retrieved from].

\section{Copyrights}

Copyright for this article is retained by the author(s), with first publication rights granted to the journal. This is an open-access article distributed under the terms and conditions of the Creative Commons Attribution license (http://creativecommons.org/licenses/by-nc/4.0). 